\title{
Analysis of a printed UWB antenna and the effects of human body in WBAN applications
}

\author{
N. Sheshaprasad ${ }^{1}$, Chandrashekar $C^{2}$, P A Vijaya ${ }^{3}$, Basavaraj I Neelgar ${ }^{4}$ \\ ${ }^{1}$ Associate Professor, Department of Electronics and Communication \\ B.N.M. Institute of Technology, Bangalore, India. \\ ${ }^{3}$ Assistant Professor, Department of Electronics and Communication \\ B.N.M. Institute of Technology, Bangalore, India. \\ ${ }^{3}$ Professor and Head, Department of Electronics and Communication \\ B.N.M. Institute of Technology, Bangalore, India. \\ ${ }^{4}$ Professor, Department of Electronics and Communication \\ B.N.M. Institute of Technology, Bangalore, India. \\ 1nsheshaprasad@bnmit.in, 2chandrashekarc@bnmit.in,3pavijaya@bnmit.in, \\ ${ }^{4}$ basavarajineelgar@bnmit.in
}

\begin{abstract}
In this paper a microstrip patch antenna with slots for desirable return loss, gain, and bandwidth was designed and tested. Fr-4 was chosen as the substrate material and the antenna was simulated using CST (Computer simulation Technology) software, printed using MITS printing machine and all the parameters were measured. The designed microstrip patch antenna has a bandwidth from 2.02 to $5.71 \mathrm{GHz}$. The proposed antenna was put on the human body and a SAR value of $1.53 \mathrm{~W} / \mathrm{kg}$ was measured, which was determined to be within the acceptable limit of $1.6 \mathrm{~W} / \mathrm{kg}$. Hence, the antenna can be used for on-body communication without causing harm to the human body.
\end{abstract}

\section{Keywords: Microstrip Patch, Ultra-Wideband, Reflection Co-efficient, SAR. \\ 1. INTRODUCTION}

Wearable devices to measure human body temperature, EEG, Blood sugar, Blood pressure etc are playing a very important role in the wireless medical applications. The antennas designed for these purposes must be placed on the human body and the characteristics of such antennas should be studied and also the effect of antenna on the human body due to the radiation of the antenna need to be analysed. There are many research going on for on-body communication [1]. At communication frequency, the human body functions as a lossy dielectric, and EM radiation produced by these antennas may penetrate semisolid objects such as living tissues [2]. The antenna models must be built and tuned in such a way that the human tissues should not be causing any negative consequences [3]. In [4], a voxel model of humans has been used which is developed in the 
CST software simulation to obtain the effect of antenna behaviour on the human skin and a microstrip patch antenna was designed that operates from 2.8 to $12 \mathrm{GHz}$ with a gain of 3.5 dBi. In [5], many feeding techniques are studied. In [6], effects of human body on antenna parameters are analysed.

\section{ANTENNA DESIGN}

The microstrip antenna was designed for a resonant frequency of $6 \mathrm{GHz}$. The size of the antenna is $30 \times 20 \times 1.6 \mathrm{~mm}^{3}$ where the size of the patch is calculated using the formula:

$$
L_{p}=W_{p}=\frac{c}{2 * f_{r} * \sqrt{\epsilon_{r}}}
$$

Apart from the patch calculation, the rest of the antenna parameters' dimensions were calculated using equations present in [7].

The dimensions of the square antenna as shown in Fig.1. The resonant length is calculated to be $11.45 \mathrm{~mm}$ and the thickness of the patch is taken as $0.035 \mathrm{~mm}$. Both the ground plane and the patch are made from copper. Fr-4 material having a dielectric constant of 4.3, was employed as the substrate because of its availability, high dielectric strength, moisture resistance, low cost, and ability to produce accurate results at higher frequencies.

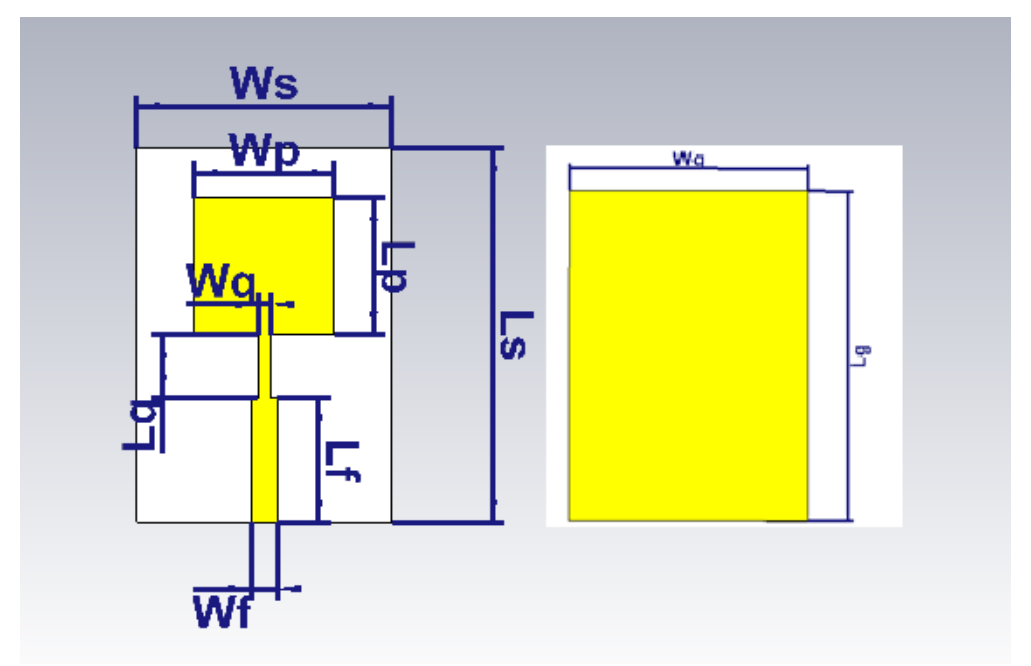

Fig 1. Structure of the Base Antenna (Front and Back View)

The square-shaped patch length was optimized to $11 \mathrm{~mm}$ to improve the reflection coefficient. Later, as illustrated in Fig.2, slots and slits were incorporated, as well as a deformation in the ground plane, enhance impedance matching, and improve the antenna's bandwidth [8-10]. The base antenna has been modified by performing different iterations introducing slits and slots on the sides of the antenna, and by reducing the ground plane to 
arrive at the proposed antenna design. The final antenna design parameters are as shown in Table 1.

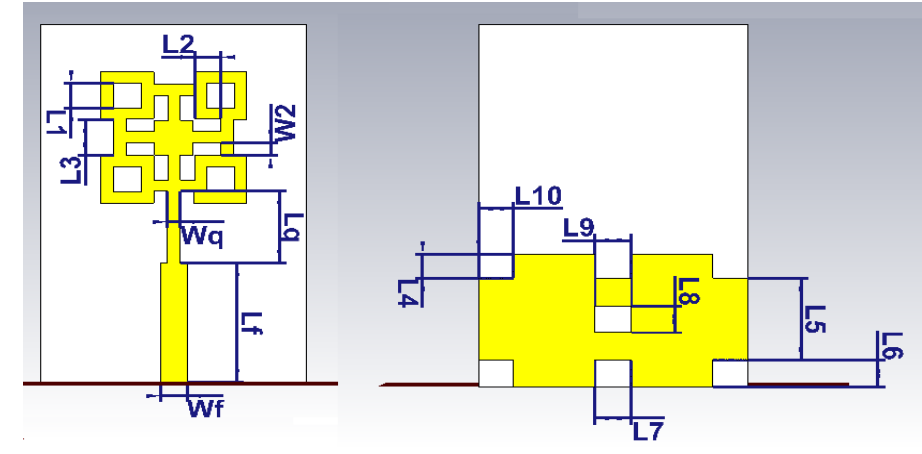

Fig 2. Structure of the Proposed Antenna (Front and Back View)

Table 1. Dimensions of the Proposed Antenna

\begin{tabular}{|c|c|}
\hline Name of the parameter & Value (in mm) \\
\hline Length of the substrate $\left(\mathrm{L}_{\mathrm{s}}\right)$ & 30 \\
\hline Length of the ground $\left(\mathrm{L}_{\mathrm{g}}\right)$ & 12 \\
\hline Width of the substrate $\left(\mathrm{W}_{\mathrm{s}}\right)$ and width of ground $(\mathrm{Wg})$ & 20 \\
\hline Length of the feed $\left(\mathrm{L}_{\mathrm{f}}\right)$ & 10 \\
\hline Width of the feed(Wf) & 2 \\
\hline Width and Length of the patch $\left(\mathrm{W}_{\mathrm{p}}=\mathrm{L}_{\mathrm{p}}\right)$ & 11 \\
\hline Height of the substrate $(\mathrm{h})$ & 1.6 \\
\hline The thickness of the patch $(\mathrm{t})$ & 0.035 \\
\hline Length of quarter wave transition (Lq) & 6 \\
\hline Width of quarter wave transition (Wq) & 1 \\
\hline W2 & 1 \\
\hline L1 & 2 \\
\hline L2 & 2 \\
\hline L3 & 3 \\
\hline L4 & 2 \\
\hline L5 & 6.8 \\
\hline L6 & 2.2 \\
\hline L7 & 2.7 \\
\hline L8 & 2.2 \\
\hline L9 & 2.7 \\
\hline L10 & 2.6 \\
\hline
\end{tabular}


The antenna was then fabricated using MITS electronics' Eleven Lab antenna printing machine at RF lab of BNMIT and the antenna was then tested for return loss $\left(\mathrm{S}_{11}\right)$ measurement using Keysight's PNA-L N5232A Network analyser at BMSCE as in Fig.3.
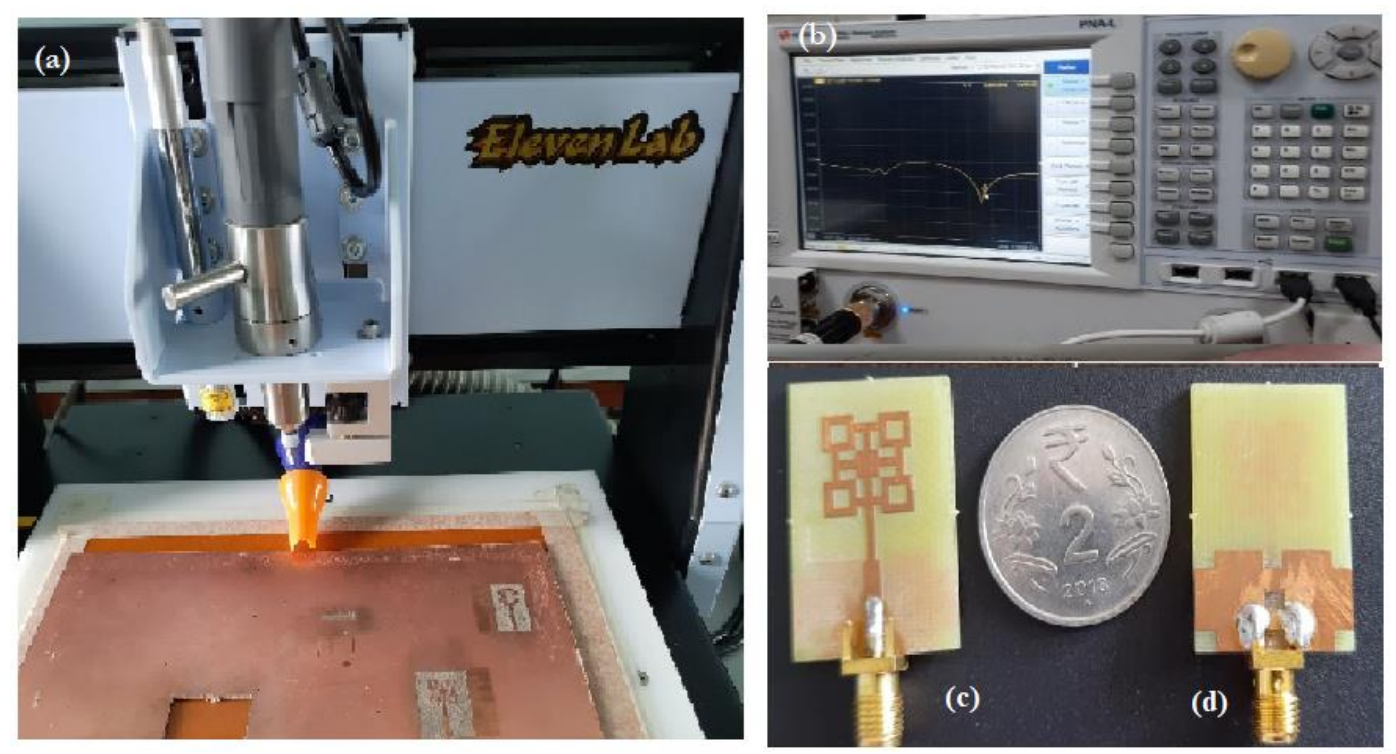

Fig. 3 Fabrication and return loss measurement setup: (a) Antenna milling Machine (b) Network analyzer (c) and (d) Front and Rear views of the printed antenna

\section{RESULT AND ANALYSIS}

The purpose of this section is to investigate the performance of the microstrip antenna in free space and on the human body. To achieve this, the antenna is simulated by using the CST Microwave Studio simulation tool. Fig.4 and Fig.5 illustrate the reflection co-efficient and the radiation pattern of the antenna in the free space.

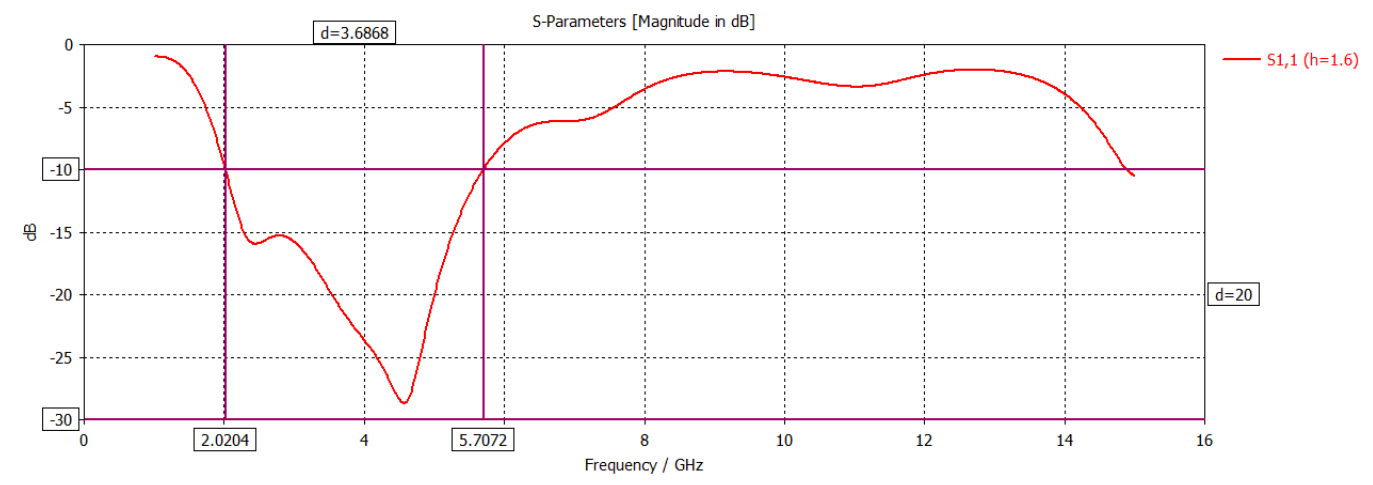

Fig 4. $S_{11}$ of the proposed antenna in Free Space 
The antenna has a wide bandwidth from 2.02 to $5.7 \mathrm{GHz}$, and it can be used for many wireless applications at $2.4 \mathrm{GHz}$ and $3.8 \mathrm{GHz}$. The antenna's return loss in free space at $2.4 \mathrm{GHz}$ is -15.26 $\mathrm{dB}$, and its directivity in free space is $2.988 \mathrm{dBi}$ and at $3.8 \mathrm{GHz}$ the return loss is $-21 \mathrm{~dB}$ and directivity is $2.981 \mathrm{dBi}$.
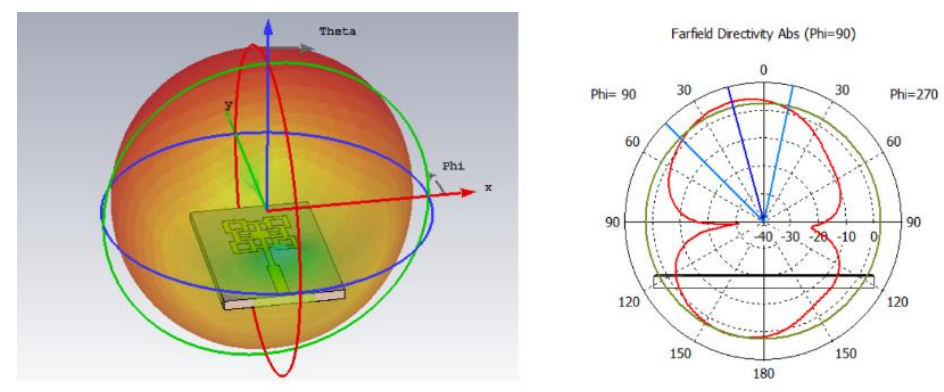

Theta / Degree vs. dis

Fig 5. Radiation pattern in free space at $2.4 \mathrm{GHz}$

Furthermore, the antenna was placed on the human model, Gustav, a 38-year-old male who is $176 \mathrm{~cm}$ and $69 \mathrm{~kg}$ as shown in Fig.6. The antenna was simulated in CST to obtain the antenna parameters and SAR value. When the antenna was placed at a distance of $1 \mathrm{~mm}$ from the human body model, the antenna detuned completely. To achieve the wide bandwidth, the antenna was moved away from the body and it was found that at $20 \mathrm{~mm}$ from the body, the return loss of the antenna was found to be similar to that of free space return loss.Fig. 7 and Fig. 8 show the reflection co-efficient and the radiation pattern of the antenna on the human body .

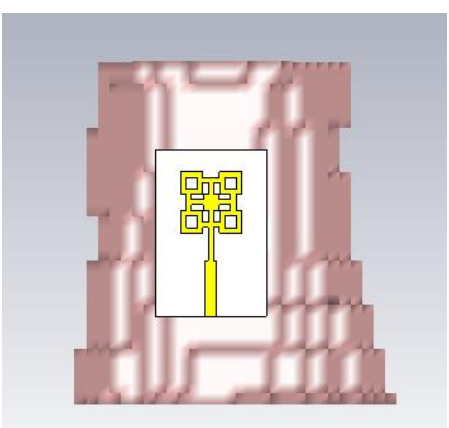

Fig 6. Antenna on the human body model Gustav

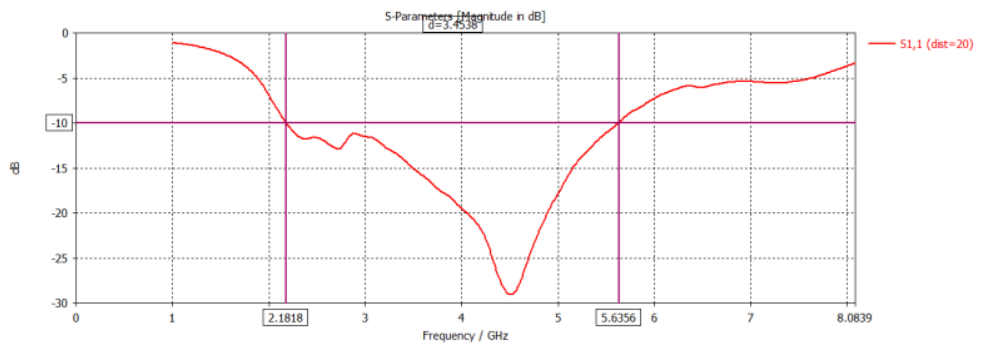

Fig 7. $S_{11}$ of antenna at a distance of $20 \mathrm{~mm}$ from the human body model 

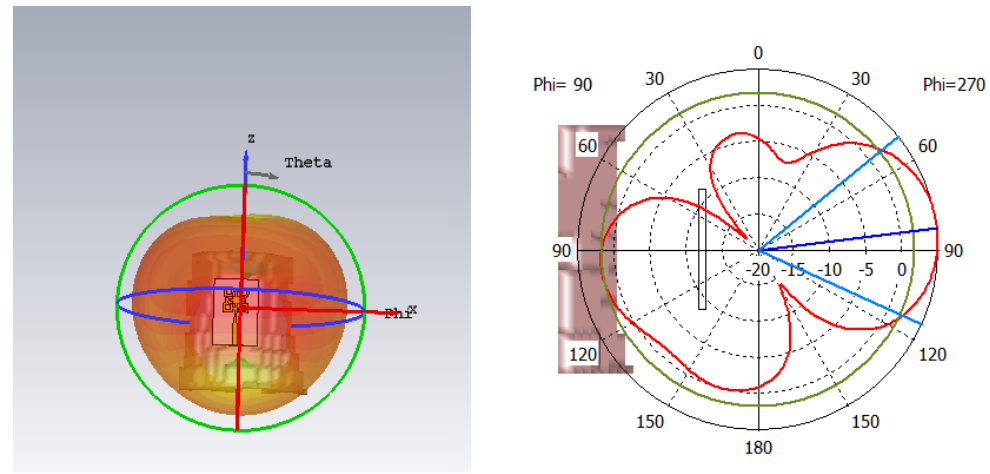

Fig 8. Radiation pattern on the human body

At a distance of $20 \mathrm{~mm}$ from the human body, the antenna was found to have a bandwidth of $2.18-5.63 \mathrm{GHz}$. The gain of the antenna on the human body is $1.601 \mathrm{dBi}$ and $1.757 \mathrm{dBi}$ at $2.4 \mathrm{GHz}$ and $3.8 \mathrm{GHz}$ respectively.

Specific Absorption Rate, also known as SAR, is a measurement of how much energy is absorbed per unit mass. The unit for SAR is $\mathrm{W} / \mathrm{kg}$. The SAR is calculated for $1 \mathrm{~g}$ at different frequencies and for different input powers are tabulated in Table 2.

Table 2. SAR of the Antenna at Different input power and frequencies

\begin{tabular}{|c|c|c|}
\hline $\begin{array}{c}\text { Input Power } \\
(\mathrm{W})\end{array}$ & Frequency $(\mathrm{GHz})$ & SAR Value $(\mathrm{W} / \mathrm{kg})$ \\
\hline \multirow{2}{*}{0.5} & 2.4 & 2.565 \\
\cline { 2 - 3 } & 3.8 & 1.298 \\
\hline \multirow{2}{*}{0.4} & 2.4 & 2.052 \\
\cline { 2 - 3 } & 3.8 & 1.03894 \\
\hline \multirow{2}{*}{0.3} & 2.4 & 1.53902 \\
\hline & 3.8 & 0.77923 \\
\hline
\end{tabular}

The SAR value of the antenna was determined to be $1.53902 \mathrm{~W} / \mathrm{kg}$ for $1 \mathrm{~g}$ of tissue at the frequency of $2.4 \mathrm{GHz}$ with an input power of $0.3 \mathrm{~W}$, as illustrated in Fig.9. The SAR value is well within the Federal Communications Commission's (FCC) public exposure standard. As a result, the suggested ultra-wideband antenna can be utilised for on-body communication. 


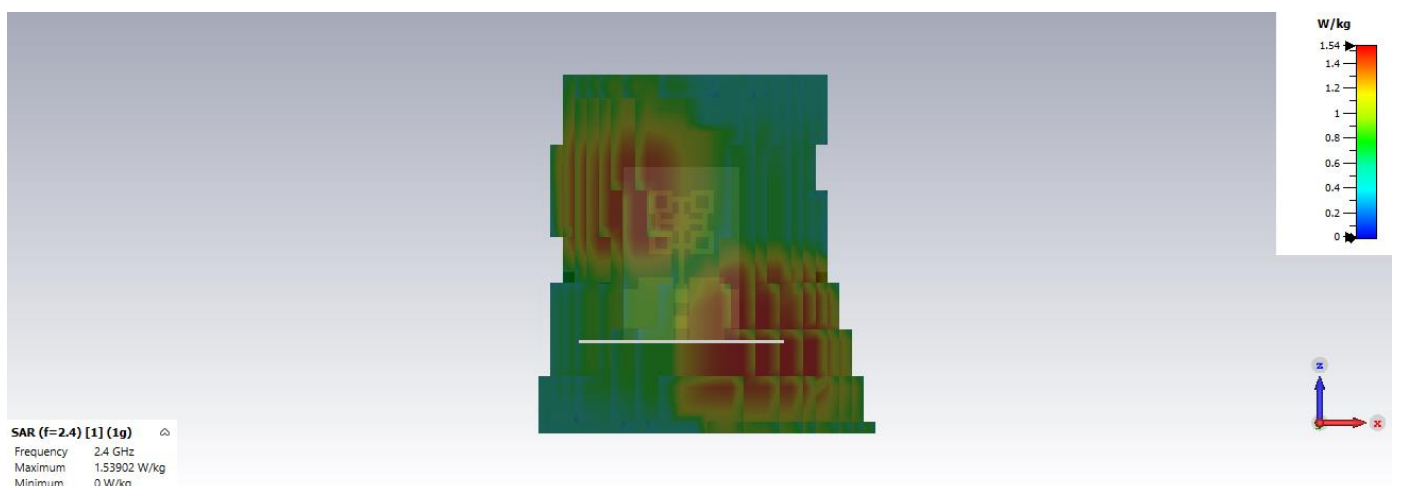

Figure 9: SAR of the Antenna for $1 \mathrm{~g}$ of tissue at $2.4 \mathrm{GHz}$

Furthermore, various parameters such as directivity, gain, VSWR, etc are measured and compared when the antenna is in free space and at a distance of $20 \mathrm{~mm}$ from the human body, which is tabulated in Table 3 .

Table 3. Antenna parameters when the antenna is in free space and on the human body.

\begin{tabular}{|c|c|c|c|c|}
\hline $\begin{array}{c}\text { Antenna } \\
\text { Parameters }\end{array}$ & $\begin{array}{c}\text { In Free } \\
\text { Space } \\
@ 2.4 \mathrm{GHz}\end{array}$ & $\begin{array}{c}\text { In Free } \\
\text { Space } \\
@ 3.8 \mathrm{Ghz}\end{array}$ & $\begin{array}{c}\text { At a distance } \\
\text { of 20mm from } \\
\text { Human } \\
\text { Body@2.4GHz }\end{array}$ & $\begin{array}{c}\text { At a distance } \\
\text { of 20mm from } \\
\text { Human } \\
\text { Body@3.8Ghz }\end{array}$ \\
\hline $\begin{array}{c}\text { Directivity } \\
\text { (in dBi) }\end{array}$ & 2.988 & 2.981 & 4.983 & 4.101 \\
\hline Gain (in dB) & 0.5073 & 0.9223 & 1.601 & 1.757 \\
\hline $\begin{array}{c}\text { Reflection } \\
\text { Coefficient (in } \\
\mathrm{dB} \text { ) }\end{array}$ & -15.26 & -21 & -11.73 & -17.64 \\
\hline $\begin{array}{c}\text { Peak Surface } \\
\text { Current } \\
\text { (in A/m) }\end{array}$ & 97.93 & 73.60 & 58.408 & 53.27 \\
\hline $\begin{array}{c}\text { VSWR } \\
\text { Radiation } \\
\text { Efficiency } \\
\text { (in dB) }\end{array}$ & -2.481 & -2.059 & -3.383 & -2.344 \\
\hline
\end{tabular}




\section{CONCLUSION}

In this work, a slotted microstrip patch antenna in the UWB band was simulated, printed and tested. Because of its compact size and ease of manufacture, this antenna is a preferable choice. Several simulated results in free space and on the human body were seen. In free space, the antenna was found to operate from $2.02 \mathrm{GHz}-5.7 \mathrm{GHz}$, with $3.68 \mathrm{GHz}$ bandwidth. On the human body, the antenna was found to operate from $2.18 \mathrm{GHz}-5.63$ $\mathrm{GHz}$, with $3.45 \mathrm{GHz}$ bandwidth. The SAR value of the antenna on the body was also well within the limit of $1.6 \mathrm{~W} / \mathrm{kg}$. Lastly, from all the results, it was understood that the antenna was capable of on-body communication and produced less detrimental effects on the human body.

\section{ACKNOWLEDGEMENT}

This work was supported by the Modernization of Advanced Communication Lab - RF, Microwave \& Antenna Design, prototype and Test Lab, BNMIT, under AICTE Grant no.9138/RIFD/MOD/policy -I/ 2018-19 dated 03.12.2019.

The authors would like to express their gratitude to Visvesvaraya Technological University, Belgaum, India, and the department of ECE at BNM Institute of Technology, Bengaluru, India, for their invaluable assistance during this project.

\section{REFERENCES}

[1] Gareth A, Conway, and William G. Scanlon, "Antennas for Over-Body Surface Communication at 2.45 GHz”, IEEE Transactions on Antennas and Propagation, VOL. 57, NO. 4, APRIL 2009.

[2] Navdeep Kaur, Rajni, "Design and Simulation of Microstrip Patch Antenna for On-Body Communication using Different Feeding Techniques", UACEE International Journal of Advancements in Electronics and Electrical Engineering - IJAEE, Volume 20132, Issue-3, September.

[3] Enrique Miralles, Carlos Andreu, Marta Cabedo-Fabrés,Miguel Ferrando-Bataller, Jose F. Monserrat, "UWB On-Body Slotted Patch Antennas for In-Body Communications", $11^{\text {th }}$ European Conference on Antennas and Propagation (EUCAP), 2017.

[4] Amin Darvazehban and Taraneh Rezaee, "Ultra-Wideband Microstrip Antenna for Body Centric Communications", ACES JOURNAL, Vol. 33, No. 3, March 2018.

[5] Sourabh Bisht, Shweta Saini, Dr. Ved Prakash, Bhaskar Nautiyal, "Study the Various Feeding Techniques of Microstrip Antenna Using Design and Simulation Using CST Microwave Studio”, International Journal of Emerging Technology and Advanced Engineering, Volume 4, Issue 9, September 2014.

[6] Shakib Rahat Chowdhury, Khaleda Ali, "Effects of Human Body on Antenna Performance: A Quantitative Study”, 19th International Conference on Computer and Information Technology, December 2016.

[7] Liton Chandra Paul, Nahid Sultan, "Design, Simulation and Performance Analysis of a Line Feed Rectangular Micro-Strip Patch Antenna”, International Journal of Engineering Sciences \& Emerging Technologies, Volume 4, Issue 2, February 2013, ISSN: 2231-6804.

[8] Udit Raithatha, S. Sreenath Kashyap, "Microstrip Patch Antenna Parameters, Feeding Techniques \& Shapes of the Patch - A Survey", International Journal of Scientific \& Engineering Research, Volume 6,

Issue 4, April-2015, ISSN 2229-5518.

[9] Huns Gregoiy Schunt, "Introduction to ultra-wideband antennas", IEEE Conference on Ultra-Wideband System and Technologies, 2003.

[10] Minh Tuan Nguyen, Byoungchul Kim, Hosung Choo, and Ikmo Park, "Effects of Ground Plane Size on a Square Microstrip Patch Antenna Designed on a Low-Permittivity Substrate with an Air Gap”, 2010 International Workshop on Antenna Technology (iWAT), March 2010 